\title{
МЕТОДИКА АНАЛИЗА ЭКОСИСТЕМНОГО РАЗНООБРАЗИЯ ЛАНДШАФТОВ РЕГИОНА ПО МАТЕРИАЛАМ ДИСТАНЦИОННОГО ЗОНДИРОВАНИЯ
}

\author{
Осипов Алексей Георгиевич1, \\ zoyaks@yandex.ru
}

Дмитриев Василий Васильевич², vasiliy-dmitriev@rambler.ru; v.dmitriev@spbu.ru

\author{
Ковязин Василий Федоровичз \\ vfkedr@mail.ru \\ 1 Военно-космическая академия им. А.Ф. Можайского, \\ Россия, 197198, г. Санкт-Петербург, ул. Ждановская, 13. \\ 2 Санкт-Петербургский государственный университет, \\ Россия, 199034, г. Санкт-Петербург, Университетская наб., 7/9. \\ 3 Санкт-Петербургский горный университет, \\ Россия, 199026, г. Санкт-Петербург, В.О., 21 линия, 2.
}

\begin{abstract}
Актуальность исследования обусловлена необходимостью сохранения ресурсо- и средовоспроизводящих функций ландшафртов при их антропогенном освоении. Одним из фракторов, способствующих устойчивости ландшафтов к антропогенным нагрузкам, является их экосистемное разнообразие. В настоящее время на практике для определения экосистемного разнообразия широко используются методы картограффического моделирования, однако они недостаточно эфффективны из-за отсутствия актуализированной крупномасштабной картограффической информации об экосистемном строении изучаемых ландшафтов.

Цель: разработать методику анализа экосистемного разнообразия ландшафтов региона с использованием материалов дистанционного зондирования и апробировать ее на территории Ленинградской области.

объекты: экосистемное разнообразие ландшафтов.

Методы: дистанционное зондирование ландшафтов; построение цифровых моделей рельефра в среде ГИС; автоматизированное дешифрирование почвенно-растительного покрова; статистическая обработка данных аэросъемки; картографические обобщения; региональный ландшафтно-экологический анализ с использованием ГИС.

Результаты. Обоснована целесообразность использования материалов дистанционного зондирования для оценки экосистемного разнообразия ландшафтов региона. Разработана модель автоматизированного дешифрирования основных типов лесного растительного покрова по его вегетационным индексам; предложен подход к определению экосистемного разнообразия по материалам автоматизированного дешифрирования основных типов лесного растительного покрова. C использованием беспилотного летательного аппарата выполнена аэрофотосъемка четырнадиати ключевых участков, выбранных в Ленинградской области. C использованием цифровой фотограмметрической системы PHOTOMOD выполнено трансформирование аэрофотоснимков. Разработан классификатор основных типов лесных растительных сообществ, характерных для изучаемой территории. Для каждого из них определены вегетационные индексы (нормализованный разностный вегетационный индекс и вегетационный индекс, скорректированный на подстилающую поверхность); выполнено автоматизированное дешисрирование основных типов лесного растительного покрова ключевых участков, и по его результатам рассчитано экосистемное разнообразие каждого из них. В среде ГИС составлена картограмма экосистемного разнообразия ландшафтов Ленинградской области.
\end{abstract}

Выводы. Разработанная авторами методика может успешно применяться при проектировании природно-антропогенных систем в различных регионах с учетом специфики их фризико-географических условий.

\section{Ключевые слова:}

Вид ландшафрта, экосистемное разнообразие, дистанционное зондирование, вегетационные индексы, типы лесных растительных сообществ, дешифровочные признаки, ключевой участок.

\section{Введение}

В настоящее время оценка, учет и сохранение экосистемного разнообразия необходимы при исследовании динамики ландшафтов и планировании их преобразований. Экосистемное разнообразие характеризует возможность выполнения ландшафтами функций жизнеобеспечения (средо- и ресурсовоспроизводства) [1-3]. Выявление потенциальных угроз для экосистемного разнообразия при проектировании антропогенной нагрузки позволит оптимизировать как размещение создаваемых объектов, так и их специализа- цию, что даст возможность снизить уровень антропогенной трансформации ландшафтов и их деградации при осуществлении хозяйственной деятельности.

Ландшафты с низким экосистемным разнообразием, при прочих равных условиях, благоприятны для антропогенного освоения. Чем выше экосистемное разнообразие, тем больше может потребоваться ресурсов для управления функционированием объекта природопользования. Любое управление, как правило, влечет за собой подавление экосистемного разнообразия, если само по себе оно не направлено на его увеличение. 
Многие исследователи отмечают, что для оценки экосистемного разнообразия целесообразно использовать данные дистанционного зондирования территории, полученные с использованием беспилотных летательных аппаратов (БПЛА) [4, 5]. При этом существующие методики, используемые для решения этой задачи, развиваются и требуют своего совершенствования.

При планировании исследования авторы исходили из того, что разработка методики анализа экосистемного разнообразия ландшафтов региона должна способствовать повышению качества и экологической безопасности проектируемых природно-антропогенных систем, что позволит обеспечить устойчивое (сбалансированное, бескризисное) развитие осваиваемых территорий.

\section{Материал и методы}

Анализ экосистемного разнообразия исследуемых ландшафтов авторы предлагают осуществлять по данным дистанционного зондирования Земли с использованием модели автоматизированного дешифрирования основных типов лесного растительного покрова по его вегетационным индексам, реализованной в среде ГИС $[6,7]$. В ее основу закладываются формализованные знания о прямых дешифровочных признаках основных типов лесных растительных сообществ и логический подход к обработке фотоизображений [8-12].

Вегетационные индексы (ВИ) - показатели, характеризующие параметры растительности, которые рассчитываются для каждого пикселя снимка в разных зонах спектра [13-15]. При этом открытая почва формирует в спектральном пространстве прямую линию, называемую почвенной, которая характеризует отсутствие растительности [16]. Для определения видового состава растительности авторы предлагают использовать два вегетационных индекса: 1) нормализованный разностный вегетационный индекс NDVI (Normalized Difference Vegetation Index) [17] и 2) вегетационный индекс, скорректированный на подстилающую поверхность, SAVI (Soil Adjusted Vegetation Index) [18].

Процесс моделирования заключается в последовательном выделении и отображении контуров основных типов лесных растительных сообществ (ТЛРС) путем сравнения между собой значений ВИ, полученных по зависимостям (1), (2) с эталонными индексами, хранящимися в базе знаний.

$$
\begin{gathered}
R_{N D V I}^{i}=\frac{1}{k} \sum_{p=1}^{k} R_{N D V I}, \\
R_{N D V I}=\left(R_{N I R}-R_{R E D}\right) /\left(R_{N I R}+R_{R E D}\right),
\end{gathered}
$$

где $p \in[1 \ldots k]$ - количество отсчетов ВИ в выборке по всем эталонным контурам ТЛРС; $R_{N D V I}^{i}-$ нормализованный разностный вегетационный индекс (НРВИ); $R_{R E D}, R_{N I R}$ - значения отраженного растительностью света в красной и ближней инфракрасной областях спектра.

$$
\begin{gathered}
R_{S A V I}^{i}=\frac{1}{k} \sum_{p=1}^{k} R_{S A V I}, \\
R_{S A V I}=\left(R_{N I R}-R_{R E D}\right) /\left(R_{N I R}+R_{R E D}+\alpha\right) \cdot(1+\alpha),
\end{gathered}
$$

где $p \in[1 \ldots k]$ - количество отсчетов ВИ в выборке по всем эталонным контурам заданных ТЛРС; $R_{S A V I}^{i}-$ вегетационный индекс, скорректированный на подстилающую поверхность; $\alpha$ - поправка на подстилающую поверхность: $\alpha \in[0, \ldots, 1]$.

Результатом дешифрирования является карта ТЛРС исследуемой территории.

Для определения экосистемного разнообразия ключевых участков видов ландшафтов предлагается использовать индекс разнообразия Симпсона, который вычисляется по формуле [19]:

$$
I_{s}=1-\sum\left(\frac{s_{i}}{S}\right)^{2},
$$

где $I_{s}$ - индекс экосистемного разнообразия; $s_{i}$ - площадь $i$-го типа лесного растительного сообщества, км² $^{2} S$ - общая площадь исследуемых лесных растительных сообществ, км²

Значения индекса разнообразия варьируют от 0 до 1. Если индекс равен нулю, то ключевой участок ландшафта содержит в себе только одно лесное растительное сообщество и, соответственно, разнообразие отсутствует. Индекс стремится к единице при возрастании числа типов лесных растительных сообществ и при увеличении равномерности их распределения.

Полученные результаты могут быть представлены в виде серии специальных картограмм [20]. В качестве базовой основы целесообразно использовать ландшафтную карту изучаемой территории. При этом тематическое содержание создаваемых картограмм может быть выражено следующими показателями: 1) площадями ландшафтов; 2) площадями, занимаемыми основными ТЛРС в пределах ландшафтов; 3) значениями экосистемного разнообразия ландшафтов.

Методика, разработанная авторами, включает в себя шесть этапов: 1) выбор в каждом виде ландшафта ключевого участка; 2) аэрофотосъемка ключевых участков видов ландшафтов с использованием БПЛА; 3) создание по материалам аэрофотосъемки фотопланов на ключевые участки видов ландшафтов; 4) формирование базы знаний для автоматизированного дешифрирования типов лесных растительных сообществ ключевых участков видов ландшафтов; 5) автоматизированное дешифрирование типов лесных растительных сообществ ключевых участков видов ландшафтов и определение их экосистемного разнообразия; 6) представление полученных результатов в картографическом виде.

\section{Результаты}

Рассмотрим результаты апробации разработанной методики на примере ключевого участка, расположенного в пределах ландшафтов озерно-ледниковых заболоченных песчаных равнин Ленинградской области. 
Первый этап. Ключевым участком будем называть часть территории вида ландшафта, выбранную для проведения детальных исследований растительного покрова с целью получения данных об основных ТЛРС и их использования для определения экосистемного разнообразия. Ключевой участок должен выбираться таким образом, чтобы на нем находились характерные представители основных ТЛРС, свой- ственных изучаемому виду ландшафта. Как правило, ключевой участок выбирается в ядре вида ландшафта, приуроченном к его центру. Площадь ключевого участка, в зависимости от сложности лесного растительного покрова, может достигать ста и более квадратных километров. На рис. 1 приведена картограмма видов ландшафтов, расположенных в пределах Ленинградской области (по А.Г. Исаченко, 1983).

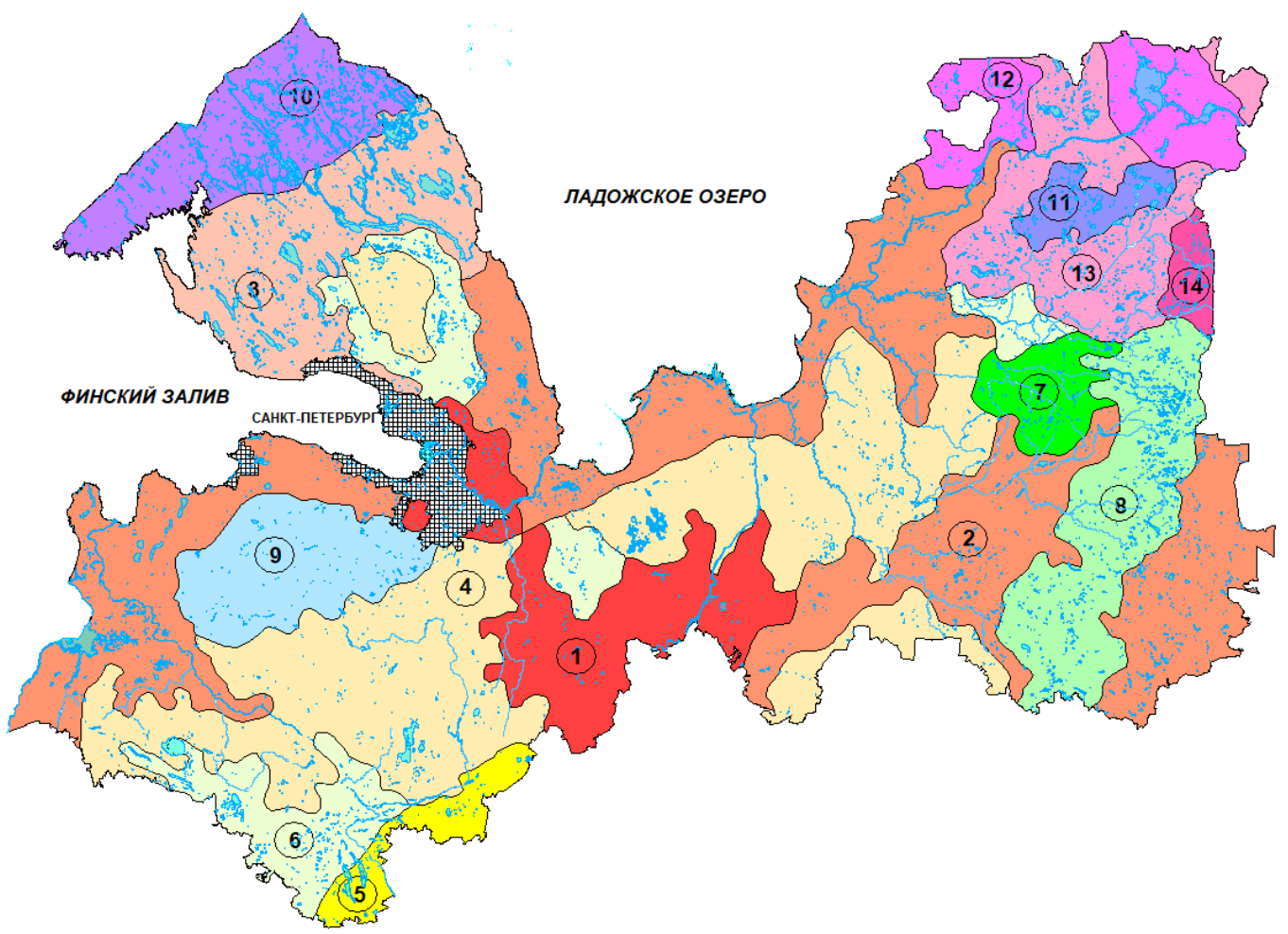

\section{ВИДЫ ЛАНДШАФТОВ \\ Ландшафты средней тайги}

Холмисто-моренные возвышенности на известняково-доломитовом плато

Холмисто-моренные возвышенности на бескарбонатных коренных породах

Низменные моренные заболоченные равнины

Низменные озерно-ледниковые заболоченные песчаные равнины

\section{Ландшафты южной тайги}

\section{Сельговые}

Известняковые карстовые плато

Холмисто-моренные возвышенности на известняково-доломитовом плато

Холмисто-моренные возвышенности на бескарбонатных коренных породах

Камовые и камово-озерно-ледниковые

Моренные заболоченные равнины на карбонатном валунном суглинке

Моренные заболоченные равнины

Озерно-ледниковые песчаные равнины с обилием озер

Озерно-ледниковые заболоченные песчаные равнины

Озерно-ледниковые заболоченные равнины

Рис. 1. Картограмма видов ландшафтов Ленинградской области

Fig. 1. Cartogram of landscape types in the Leningrad region

Bторой этап. Аэрофотосъемка ключевых участков осуществлялась с использованием БПЛА, оснащенного мультиспектральной камерой Tetracam ADC Micro. Камера обеспечивает разрешение простран- ственных данных до 10 см, имеет память 2 Гб (с возможным расширением до 8 Гб), быструю параллельную обработку данных, сверхнизкое потребление энергии, простую систему управления и контроля, 
3.2 Мп матрицу, способную улавливать волны в видимом спектре длиной более 520 нм и волны в ближней инфракрасной области спектра длиной до 920 нм. Камера и поставляемое с ней программное обеспечение «PixelWrench2» хорошо подходят для получения и обработки мультиспектральных изображений посевов и лесов, а также изучения различных экосистем.

Аэрофотосъемка производилась в двух зонах спектра - красной $\left(\lambda_{\mathrm{RED}}=0,68-0,7\right.$ мкм $)$ и ближней инфракрасной $\left(\lambda_{\mathrm{NIR}}=0,74-1,1\right.$ мкм) и характеризовалась следующими параметрами: перепады высот в пределах маршрутов составляли от 250 до 550 м; средняя величина продольных и поперечных пере-

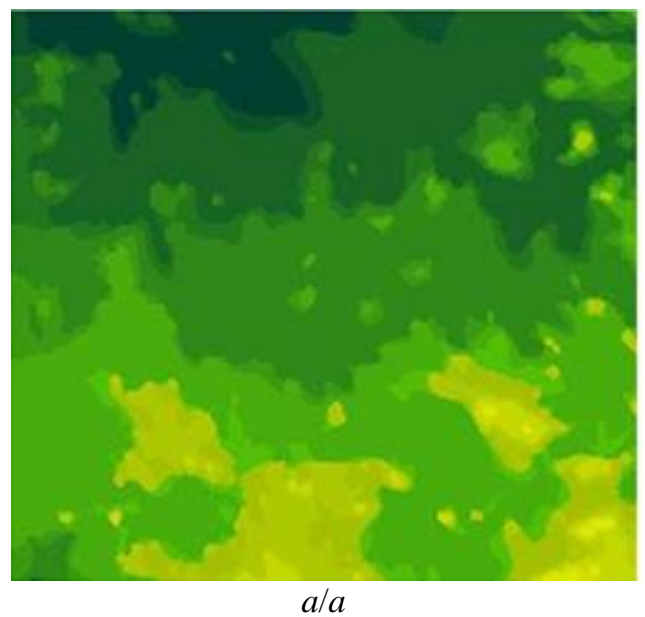

крытий кадров колебалась в пределах от 28 до 96 \%; ширина обзора изменялась в пределах от 170 до 380 м. Управление БПЛА выполнялось с наземного пункта управления по радиоканалам. Положение летательного аппарата во время полета фиксировалось на электронной карте, отображаемой на экране монитора.

Tретий этап. Трансформирование отдельных снимков и объединение полученных растров в единое геоинформационное пространство выполнялось с использованием цифровой фотограмметрической системы PHOTOMOD. Для учета рельефа была построена его цифровая модель, фрагмент которой приведен на рис. 2.

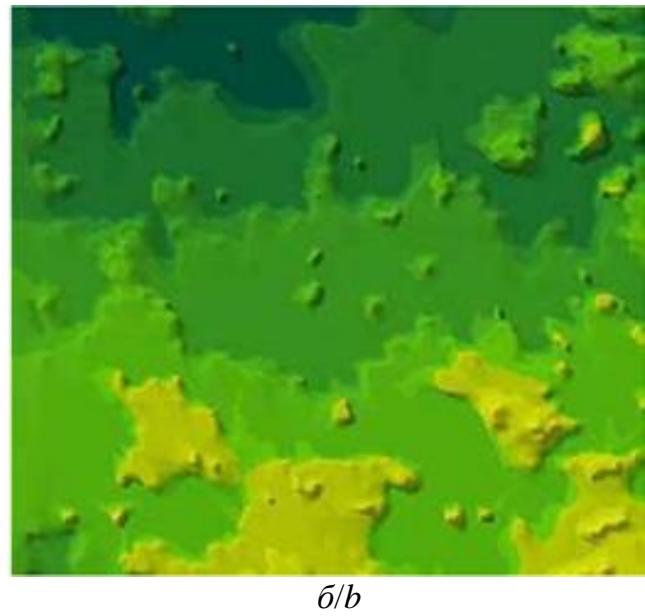

Шкала высот в метрах

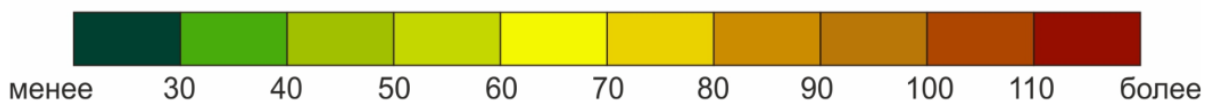

Pис. 2. Фрагмент иифровой модели рельефа, созданной на исследуемый ключевой участок ( $а$-без отмывки; б-c отмывкой)

Fig. 2. Fragment of a digital terrain model created for the key area under study ( $a$-without washing; $b$ - with washing)

В качестве картографической основы для создания цифровой модели рельефа использовалась топографическая карта масштаба 1:50000. Шаг дискретизации цифровой модели составлял 30 м. Ее создание осуществлялось в среде ГИС «Карта 2011».

Трансформирование снимков осуществлялось аналитическим методом, основанным на использовании коллинеарных уравнений, описывающих закон построения изображения для одиночного снимка в центральной проекции [21]. Точность трансформирования при высоте сечения рельефа 5 м составила 8 м для равнинных участков местности и 10 м для холмистых.

Результатом работ явились координатнопривязанные фотопланы на ключевые участки видов ландшафтов в виде двух геометрически идентичных, но различных по спектральным образам, трансформированных изображений.

Четвертый этап. Для систематизации информации об основных ТЛРС был разработан их классификатор с использованием фондовых материалов ландшафтных исследований, данных лесоустроительной документации и лесного кадастра. В качестве объектов классификатора были приняты следующие типы лесных растительных сообществ: 1) сосновые сухие леса; 2) сосновые избыточно увлажненные леса; 3) елово-сосновые сухие леса; 4) елово-березовые сухие леса; 5) елово-березовые избыточно увлажненные леса; 6) березовые сухие леса; 7) редкостойные угнетенные заболоченные леса; 8) луга; 9) болота.

Для ТЛРС, входящих в классификатор, были определены следующие показатели: нормализованный разностный вегетационный индекс (1) и вегетационный индекс, скорректированный на подстилающую поверхность (3).

Пятый этап. Автоматизированное дешифрирование основных ТЛРС в пределах ключевых участков ландшафтов осуществлялось с использованием программного обеспечения, разработанного специалистами военно-космической академии имени А.Ф. Можайского. Дешифрирование заключалось в последовательном выделении их контуров путем сравнения, рассчитанных по фотоизображению значений ВИ с индексами, хранящимися в базе знаний $[22,23]$, и сегментации полученной информации. Процесс сегментации в программном обеспечении реализован следующим образом. Методом «ближай- 
ших соседей» выполняется предварительная сегментация областей в матрице НРВИ с равными индексами с установлением принадлежности выделенного кластера ТЛРС. В результате чего формируется набор картограмм, элементами которых являются коды ТЛРС. Для оконтуривания каждого массива кодов используется метод «наименьшего однородного сегмента, ассимилируемого ядром». Отслеживание контура осуществляется путем перемещения окна по границе ядра вдоль контура объекта и проверки площади захвата на каждом шаге. Изменение направления перемещения окна выполняется в случае уменьшения площади более чем на $10 \%$.

Для оценки точности дешифрирования была составлена матрица, в которой классы типов лесной растительности, полученные по аэрофотоснимкам, сравнивались с классами, полученными по материалам полевого обследования (4).

$$
Q=\frac{\sum_{i=1}^{n} D i}{N} \times 100,
$$

где $Q$ - обобщенный показатель точности автоматизированного дешифрирования растительных сообществ по аэрофотоснимкам; $D_{i}-$ значение $i$-го диагонального элемента; $n$ - общее количество диагональных элементов; $N$ - общее количество анализируемых образов.

Процент совпадения классов от общего количества анализируемых образов был принят в качестве значения точности автоматизированного дешифрирования.

Обобщенный показатель точности автоматизированного дешифрирования основных ТЛРС ключевых участков составил $85,3 \%$, т. е. в 85 случаев из 100 отдешифрированные основные ТЛРС совпадали с реальными сообществами.

В качестве примера на рис. 3 приведен фрагмент картограммы основных ТЛРС исследуемого ключевого участка, составленной по фотоплану.

По созданной картограмме были определены площади основных ТЛРС исследуемого ключевого участка (таблица).

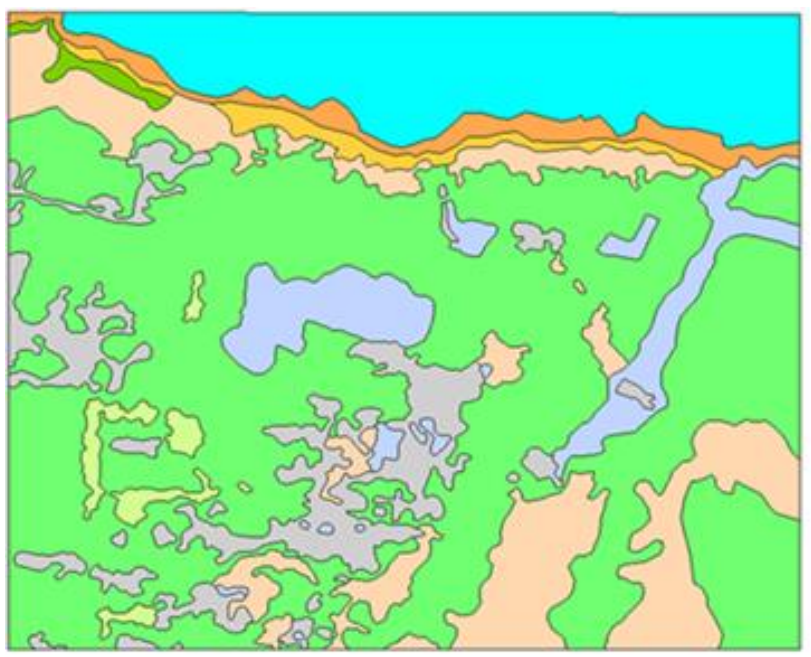

\author{
Условные обозначения \\ антропогенно нарушенные территорин \\ водные объекты \\ 6onota \\ епово-березовые избыточно увлакненые песа \\ березовые избыточно увлакненыые песа \\ сосновые избыточно увламненые песа \\ enoвo-6ерезовые сумие nеса \\ епово-сосновы сулан песа \\ cochobsie cysue neca
}

Рис. 3. Фрагмент картограммы основных ТЛРС исследуемого ключевого участка, составленный по фотоплану

Fig. 3. Fragment of the cartogram of the main types of forest plant communities (TFPC) of the key area under study, compiled from the photoplane

Таблица. Площчади основных ТЛРС исследуемого ключевого участка

Table. $\quad$ Areas of the main TFPC of the key area under study

\begin{tabular}{|c|c|c|}
\hline $\begin{array}{l}\text { Коды типов } \\
\text { Туре code }\end{array}$ & $\begin{array}{l}\text { Название основных ТЛРС } \\
\text { Name of the main ТFРС }\end{array}$ & $\begin{array}{l}\text { Площади типов, км² } \\
\text { Туре areas, } \mathrm{km}^{2}\end{array}$ \\
\hline 1 & $\begin{array}{l}\text { Сосновые сухие леса } \\
\text { Dry pine forests }\end{array}$ & 5,34 \\
\hline 2 & $\begin{array}{l}\text { Елово-сосновые сухие леса } \\
\text { Spruce-pine dry forests }\end{array}$ & 3,44 \\
\hline 3 & $\begin{array}{l}\text { Елово-березовые сухие леса } \\
\text { Spruce-birch dry forests }\end{array}$ & 1,44 \\
\hline 4 & $\begin{array}{l}\text { Сосновые избыточно увлажненные леса } \\
\text { Pine forests with excessive moisture }\end{array}$ & 11,87 \\
\hline 5 & $\begin{array}{l}\text { Березовые избыточно увлажненные леса } \\
\text { Birch over-humidified forests }\end{array}$ & 2,27 \\
\hline 6 & $\begin{array}{l}\text { Елово-березовые избыточно увлажненные леса } \\
\text { Spruce-birch over-humidified forests }\end{array}$ & 38,45 \\
\hline 7 & \begin{tabular}{|l|} 
Болота \\
Swamps
\end{tabular} & 6,38 \\
\hline \multicolumn{2}{|c|}{$\begin{array}{l}\text { Общая площадь основных ТЛРС на исследуемом ключевом участке } \\
\text { Total area of the main TFPC in the key area under study }\end{array}$} & 69,17 \\
\hline
\end{tabular}


Для определения экосистемного разнообразия ключевых участков видов ландшафтов была использована формула (3). Для исследуемого ключевого участка экосистемное разнообразие составило 0,64 .

Шестой этап. После определения экосистемного разнообразия ключевых участков видов ландшафтов всем индивидуальным ландшафтам, входящим в соответствующие виды, присваиваются вычисленные значения экосистемного разнообразия и на этой основе создаются картограммы экосистемного разнообразия ландшафтов (рис. 4).

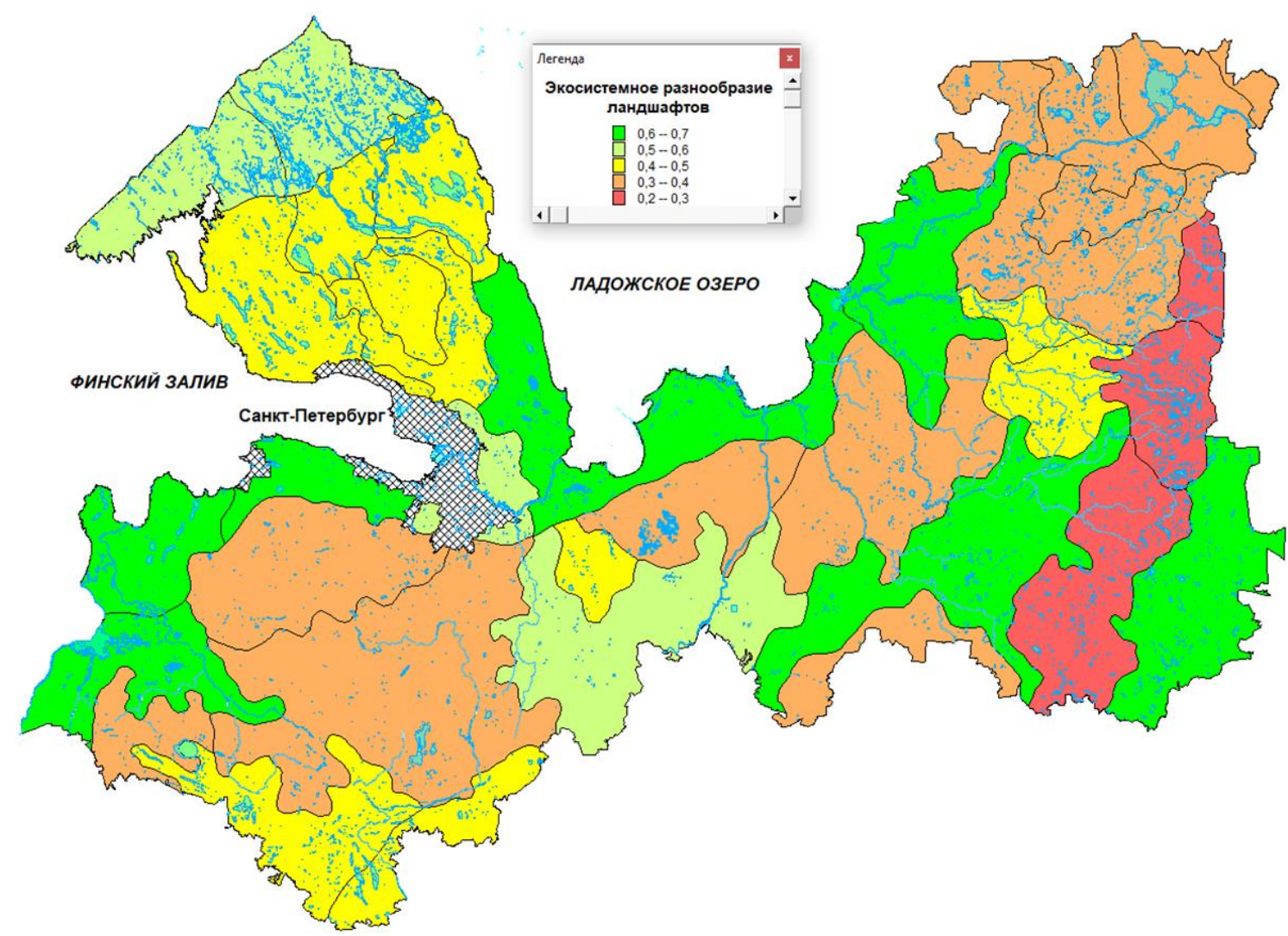

Pис. 4. Картограмма экосистемного разнообразия ландшафтов Ленинградской области

Fig. 4. Cartogram of ecosystem diversity of landscapes of the Leningrad region

\section{Заключение}

Рассмотренная выше методика позволяет получать актуализированную информацию об экосистемном разнообразии ландшафтов изучаемого региона. Заложенные в ее основу подходы базируются на исследованиях, проведенных авторами с 2013 г. по настоящее время [23-25], которые были доложены на всероссийских и международных конференциях, где получили поддержку и одобрение.

В предыдущих исследованиях внимание авторов было сосредоточено на отдельных аспектах данной работы, включая: разработку научно-методических основ анализа экосистемного разнообразия [23], использование беспилотных летательных аппаратов для изучения зеленых насаждений [25], разработку подходов к ландшафтноэкологическому районированию земель [24].

В данной статье на основе обобщения результатов ранее выполненных авторами работ сформулированы теоретические положения анализа экосистемного разнообразия ландшафтов региона и приведены подходы к его практическому применению. Полученные авторами результаты полностью соответствуют цели и задачам исследования.
Рассматриваемой тематике посвящены работы $[8,19]$. В работе [8] для оценки экосистемного разнообразия используется картографическая информация. Этот подход интересен, однако он зачастую трудно реализуем изза отсутствия актуализированных крупномасштабных карт об экосистемном строении изучаемой территории. В работе [19] автор рассматривает особенности не экосистемного, а ландшафтного разнообразия.

Разработанная авторами методика была успешно апробирована при геоэкологической оценке пригодности территории Киришского муниципального района Ленинградской области для рекреационного освоения [26]. Результаты апробации доказали работоспособность методики и возможность ее применения при проектировании природно-антропогенных систем в различных регионах с учетом специфики их физикогеографических условий; при решении оптимизационных эколого-экономических задач природопользования; при выполнении землеустроительных работ и при разработке схем территориального планирования.

Исследование выполнено при финансовой поддержке РФФИ в рамках научного проекта № 19-05-00683-а. 


\section{СПИСОК ЛИТЕРАТУРЫ}

1. Факторы формирования ландшафтного разнообразия природного парка «Предгорье Алтая» и пути его сохранения / О.Н. Барышникова, И.Н. Ротанова, М.М. Силантьева, Н.Ф. Харламова // ActaBiologicaSibirica. - 2017. - Т. 3. № 3. - C. 23-31.

2. Огуреева Г.Н. Экосистемное и биотическое разнообразие Прикаспийского региона // Юг России: экология, развитие. 2018. - T. 13. - № 4. - C. 8-23. DOI: 10.18470/1992-1098-2018-4-8-23.

3. Ковязин В.Ф., Кан К.Х., Фам Т.К. Оценка видового состава древесных растений в ландшафтах Павловского парка СанктПетербурга // Известия высших учебных заведений. Лесной журнал. - 2017. - № 5. - С. 82-91. DOI: 10.17238/issn05361036.2017 .5 .82

4. Черненькова Т.В. Оценка биоразнообразия лесов наземными и дистанционными методами на основе ГИС-технологий // Биосфера. - 2009. - № 1. - С. 129-136.

5. Everaerts J. The Use of Unmanned Aerial Vehicles (UAVS) for remote sensing and mapping // The International Archives of the Photogrammetry, Remote Sensing and Spatial Information Sciences (ISPRS Congress), XXXVII (B1). - Beijing, China, 2008. - P. 1187-1192.

6. Foody G.M. GIS: biodiversity applications // Progress in Physical Geography. - 2008. - V. 32 (2). - P. 223-235.

7. Coupling GIS and LCA for biodiversity assessments of land use / J.P. Geyer, D.M. Stoms, F.W. Davis, B. Wittstock // International Journal of Life Cycle Assessment. - 2010. - V. 15. - P. 692-703.

8. Колбовский Е.Ю., Есипова Е.С. Геоинформационное моделирование ландшафтных местоположений и элементарных водосборов для оценки потенциального биоразнообразия лесной зоны Дальнего Востока // Геодезия и картография. - 2017. № 1. - С. 25-34.

9. Малых О.Ф. К оценке индикаторов экосистемного разнообразия горнотаёжных сосняков южносибирского типа Забайкальского края // Успехи современного естествознания. - 2018. № 8. - C. 160-165.

10. Ji L., Peters A.J. Performance evaluation of spectral vegetation indices using a statistical sensitivity function // Remote Sensing of Environment. - 2007. - V. 106 (1). - P. 59-65.

11. Geostatistical estimation of signal-to-noise ratios for spectral vegetation indices / J. Lei, L. Zhang, J. Rover, B.K. Wylie, $X$. Chen // ISPRS Journal of Photogrammetry and Remote Sensing. - 2014. - V. 96. - P. 20-27.

12. Le Maire G., Francois C., Dufrene E. Towards universal broad leaf chlorophyll indices using PROSPECT simulated database and hyperspectral reflectance measurements // Remote Sensing of Environment. - 2004. - V. 89. - P. 1-28.

13. Братков В.В. Атаев 3.В. Вегетационные индексы и их использование для картографирования горных ландшафтов Российского Кавказа // APRIORI. Серия: Естественные и технические науки. - 2017. - № 1. - С. 1-21.
14. Черепанов А.С., Дружинина Е.Г. Спектральные свойства растительности и вегетационные индексы // Геоматика. 2009. - № 3. - C. 1-5.

15. The interpretation of spectral vegetation indexes / R.B. Myneni, F.G. Hall, P.J. Sellers, A.L. Marshak // IEEE Transactions on Geoscience and Remote Sensing. - 1995. - V. 33. - Iss. 2. P. 481-486.

16. Richardson A.J., Wiegand C.L. Distinguishing vegetation from soil background information // Photogrammetric Engineering and Remote Sensing. - 1977. - V. 43. - Iss. 12. - P. 1541-1552.

17. Elvidge C.D., Lyon R.J.P. Influence of rock-soil spectral variation on the assessment of green biomass // Remote Sensing of Environment. - 1985. - V. 17. - P. 265-269.

18. Huete A.R. A Soil-Adjusted Vegetation Index (SAVI) // Remote Sensing of Environment. - 1988. - V. 25. - P. 295-309.

19. Соколов А.С. Картографический анализ региональных особенностей ландшафтного разнообразия Белоруссии // Псковский регионологический журнал. - 2016. - № 4 (28). - С. 59-70.

20. Васильев О.Д., Чистов С.В. Исследование и картографирование экологических функций лесов Московского региона: методика и результаты // ИнтерКарто. ИнтерГИС. - 2018. Т. 24. - № 1. - С. 348-367.

21. Тимофеев В.Г. Использование дистанционно-пилотируемых летательных аппаратов для оперативного выявления изменений местности // Тезисы докладов научно-технической конференции ФГУП «РНИИ КП», посвященной 60-летию предприятия. - М., 10-12 октября 2006. - С. 310-312.

22. Волгушева Н.Э., Прокофьев Н.А., Бляхарский Д.П. Технология расчета вегетационного индекса на основании данных беспилотной аэрофотосъёмки // Известия высших учебных заведений. Геодезия и аэрофотосъемка. - 2016. - № 2. - С. 71-76.

23. Осипов А.Г., Тимофеев В.Г. Научно-методические основы определения экологически допустимого уровня освоения природных ландшафтов при создании природно-аграрных систем // Информация и космос. - 2015. - № 2. - С. 85-95.

24. Ландшафтно-экологическое районирование и мониторинг земель Ленинградской области / Н.В. Арефьев, В.В. Гарманов, А.Г. Осипов, В.Е. Трушников // Горный информационноаналитический бюллетень (научно-технический журнал) 2013. - № 11. - С. 303-311.

25. Мониторинг зеленых насаждений с применением беспилотных летательных аппаратов / В.Ф. Ковязин, В.Л. Богданов, В.В. Гарманов, А.Г. Осипов // Аграрный научный журнал. 2016. - № 4. - С. 14-19.

26. Осипов А.Г., Долгова М.П. Геоэкологическая оценка пригодности территории Будогощского городского поселения Киришского муниципального района Ленинградской области для рекреационного освоения // Информация и космос. 2014. - № 3. - C. 72-79

Поступила: 09.03.2020 г.

\section{Информация об авторах}

Осипов A.Г., кандидат географических наук, доцент кафедры картографии Военно-космической академии им. А.Ф. Можайского.

Дмитриев В.В., доктор географических наук, профессор кафедры гидрологии суши Института наук о Земле Санкт-Петербургского государственного университета.

Ковязин В.Ф., доктор биологических наук, профессор кафедры инженерной геодезии, Санкт-Петербургский горный университет. 
UDC 502.5

\title{
METHODS OF ANALYZING LANDSCAPE ECOSYSTEM DIVERSITY OF A REGION BASED ON REMOTE SENSING
}

\author{
Alexey G. Osipov ${ }^{1}$, \\ zoyaks@yandex.ru \\ Vasiliy V. Dmitriev², \\ vasiliy-dmitriev@rambler.ru; v.dmitriev@spbu.ru \\ Vasily F. Kovyazin ${ }^{3}$, \\ vfkedr@mail.ru \\ 1 Military Space Academy named after A.F. Mozhaisky, \\ 13, Zhdanovskaya street, St. Petersburg, 195279, Russia. \\ 2 St. Petersburg State University, \\ 7/9, Universitetskaya embankment, St. Petersburg, 199034, Russia. \\ 3 St. Petersburg Mining University, \\ 2, Vasilyevsky Island 21 line, St. Petersburg, 199026, Russia.
}

The relevance of the research is caused by the need to preserve the resource- and environment-reproducing functions of landscapes during their anthropogenic development. One of the factors contributing to the resilience of landscapes to anthropogenic loads is their ecosystem diversity. Currently, cartographic modeling methods are widely used in practice to determine ecosystem diversity, but they are not effective enough due to the lack of updated large-scale cartographic information about the ecosystem structure of the studied landscapes.

The aim of the research is to develop a methodology for analyzing the ecosystem diversity of the region's landscapes using remote sensing materials and to test it on the territory of the Leningrad region.

Objects: ecosystem diversity of landscapes.

Methods: remote sensing of landscapes; construction of digital terrain models in the GIS environment; automated interpretation of soil and vegetation cover; statistical data processing, aerial surveys; cartographic generalizations; regional landscape and environmental analysis using GIS.

Results. The expediency of using remote sensing materials to assess the ecosystem diversity of the region's landscapes is substantiated. A model of automated interpretation of the main types of forest vegetation cover based on its vegetation indices is developed; an approach to determining ecosystem diversity based on the materials of automated interpretation of the main types of forest vegetation cover is proposed. Aerial photography of fourteen key sites selected in the Leningrad region was performed using an unmanned aerial vehicle. Aerial photos were transformed using the digital photogrammetric system PHOTOMOD. A classifier of the main types of forest plant communities characteristic of the study area was developed. Vegetation indices were determined for each of them (normalized difference vegetation index and vegetation index adjusted for the underlying surface); automated decoding of the main types of forest vegetation cover in key areas was performed and the ecosystem diversity of each of them was calculated based on its results. In the GIS environment, a cartogram of the ecosystem diversity of the landscapes of the Leningrad region was compiled.

Summary. The method developed by the authors can be successfully applied in the design of natural and anthropogenic systems in various regions, taking into account the specifics of their physical and geographical conditions.

\section{Key words:}

Landscape type, ecosystem diversity, remote sensing, vegetation indices, types of forest plant communities, decoding features, key site.

The research was financially supported by the RFBR within the scientific project no. 19-05-00683-a.

\section{REFERENCES}

1. Baryshnikova O.N., Rotanova I.N., Silantieva M.M., Kharlamova N.F. Factors of formation of landscape diversity of the natural Park «Foothills of Altai» and ways of its preservation. ActaBiologicaSibirica, 2017, vol. 3, no. 3, pp. 23-31. In Rus.

2. Ogureeva G.N. Ecosystem and biotic diversity of the Caspian region] South of Russia: ecology and development. Kamerton publishing house, 2018, vol. 13, no. 4, pp. 8-23. In Rus. DOI: $10.18470 / 1992-1098-2018-4-8-23$.

3. Kovyazin V.F., Kan K.H., Pham T.K. Assessment of the species composition of woody plants in the landscapes of Pavlovsk Park in Saint Petersburg. News of higher educational institutions. Forest magazine, 2017, no. 5, pp. 82-91. In Rus. DOI: 10.17238/issn0536-1036.2017.5.82.

4. Chernenkova T.V. Otsenka bioraznoobraziya lesov nazemnymi i distantsionnymi metodami na osnove GIS-tekhnologiy [Assess- ment of forest biodiversity by ground and remote methods based on GIS technologies]. Biosfera, 2009, no. 1, pp. 129-136.

5. Everaerts J. The Use of Unmanned Aerial Vehicles (UAVS) for remote sensing and mapping. The International Archives of the Photogrammetry, Remote Sensing and Spatial Information Sciences (ISPRS Congress), XXXVII (B1). Beijing, China, 2008. pp. 1187-1192.

6. Foody G.M. GIS: biodiversity applications. Progress in Physical Geography, 2008, vol. 32 (2), pp. 223-235.

7. Geyer J.P., Stoms D.M., Davis F.W., Wittstock B. Coupling GIS and LCA for biodiversity assessments of land use. International Journal of Life Cycle Assessment, 2010, vol. 15, pp. 692-703.

8. Kolbowski E.J., Esipova E.S. Geoinformation modeling of landscape locations and elementary catchments to assess the potential biodiversity of the forest zone of the Far East. Geodesy and cartography, 2017, no. 1, pp. 25-34. In Rus. 
9. Malyh O.F. To assess indicators of ecosystem diversity of mountain taiga pine forests of the South Siberian type of the TRANS Baikal territory. Successes of modern natural science, 2018, no. 8, pp. 160-165. In Rus.

10. Ji L., Peters A.J. Performance evaluation of spectral vegetation indices using a statistical sensitivity function. Remote Sensing of Environment, 2007, vol. 106 (1), pp. 59-65.

11. Lei J., Zhang L., Rover J., Wylie B.K., Chen X. Geostatistical estimation of signal-to-noise ratios for spectral vegetation indices. ISPRS Journal of Photogrammetry and Remote Sensing, 2014, vol. 96 , pp. 20-27.

12. Le Maire G., Francois C., Dufrene E. Towards universal broad leaf chlorophyll indices using PROSPECT simulated database and hyperspectral reflectance measurements. Remote Sensing of Environment, 2004, vol. 89, pp. 1-28.

13. Bratkov V.V., Ataev Z.V. Vegetatsionnye indeksy i ikh ispolzovanie dlya kartografirovaniya gornykh landshaftov Rossiyskogo Kavkaza [Vegetation indices and their use for mapping mountain landscapes of The Russian Caucasus]. APRIORI. Series: Natural and technical Sciences, 2017, no. 1, pp. 1-21.

14. Cherepanov A.S., Druzhinina E.G. Spektralnye svoystva rastitelnosti i vegetatsionnye indeksy [Spectral properties of vegetation and vegetation indices]. Geomatic, 2009, no. 3, pp. 1-5.

15. Myneni R.B., Hall F.G., Sellers P.J., Marshak A.L.The interpretation of spectral vegetation indexes. IEEE Transactions on Geoscience and Remote Sensing, 1995, vol. 33, no. 2, pp. 481-486.

16. Richardson A.J., Wiegand C.L. Distinguishing vegetation from soil background information. Photogrammetric Engineering and Remote Sensing, 1977, vol. 43, no. 12, pp. 1541-1552.

17. Elvidge C.D., Lyon R.J. Influence of rock-soil spectral variation on the assessment of green biomass. Remote Sensing of Environment, 1985, vol. 17, pp. 265-269.

18. Huete A.R. A Soil-Adjusted Vegetation Index (SAVI). Remote Sensing of Environment, 1988, vol. 25, pp. 295-309.

19. Sokolov A.S. Cartographic analysis of regional features of landscape diversity in Belarus. Pskov regionological journal, 2016, no. 4 (28), pp. 59-70. In Rus.

20. Vasiliev O.D., Chistov S.V. Research and mapping of ecological functions of forests in the Moscow region: methods and results. $I n$ terCarto. InterGis, 2018, vol. 24, no. 1, pp. 348-367. In Rus.
21. Timofeev V.G. Ispolzovanie distantsionno-pilotiruemykh letatelnykh apparatov dlya operativnogo vyyavleniya izmeneniy mestnosti [Use of remotely piloted aircraft for rapid detection of terrain changes]. Tezisy dokladov nauchno-tekhnicheskoy konferentsii RNII KP, posvyashchennoy 60-letiyu predpriyatiya [Abstracts of the scientific and technical conference of RNII KP dedicated to the $60^{\text {th }}$ anniversary of the enterprise]. Moscow, October 10-12, 2006. pp. 310-312

22. Volgusheva N.E., Prokofiev N.A., Blacharski D.P. Technology for calculating the vegetation index based on data from unmanned aerial photography. News of higher educational institutions. Geodesy and aerial photography, 2016, no. 2, pp. 71-76. In Rus.

23. Osipov A.G., Timofeev V.G. Nauchno-metodicheskie osnovy opredeleniya ekologicheski dopustimogo urovnya osvoeniya prirodnykh landshaftov pri sozdanii prirodno-agrarnykh sistem [Scientific and methodological basis for determining the environmentally acceptable level of development of natural landscapes when creating natural and agricultural systems]. Information and space, 2015, no. 2, pp. 85-95.

24. Arefyev N.V., Garmanov V.V., Osipov A.G., Trushnikov V.E. Landshaftno-ekologicheskoe rayonirovanie i monitoring zemel Leningradskoy oblasti [Landscape and environmental zoning and monitoring of land in the Leningrad region]. Mining information and analytical Bulletin (scientific and technical journal), 2013, no. 11 , pp. 303-311

25. Kovyazin V.F., Bogdanov V.L., Garmanov V.V., Osipov A.G. Monitoring zelenykh nasazhdeniy s primeneniem bespilotnykh letatelnykh apparatov [Monitoring of green plantations with the use of unmanned aerial vehicles]. Agricultural scientific journal, 2016, no. 4, pp. 14-19.

26. Osipov A.G., Dolgova M.P. Geoekologicheskaya otsenka prigodnosti territorii Budogoschskogo gorodskogo poseleniya Kirishskogo munitsipalnogo rayona Leningradskoy oblasti dlya rekreatsionnogo osvoeniya [Geoecological assessment of the suitability of the site Budogoshch urban settlement of Kirishi municipal district of Leningrad region for recreational use]. Information and space, 2014, no. 3, pp. 72-79.

Received: 9 March 2020.

Information about the authors

Alexey G. Osipov, Cand. Sc., associate professor, Military Space Academy named after A.F. Mozhaisky.

Vasiliy V. Dmitriev, Dr. Sc., professor, St. Petersburg State University.

Vasily F. Kovyazin, Dr. Sc., professor, St. Petersburg Mining University. 